INTERVENTIONAL CARDIOLOGY AND SURGERY

\title{
Recovery of impaired microvascular function in collateral dependent myocardium after recanalisation of a chronic total coronary occlusion
}

\author{
G S Werner, U Emig, P Bahrmann, M Ferrari, H R Figulla
}

Heart 2004;90:1303-1309. doi: 10.1136/hrt.2003.024620

See end of article for authors' affiliations

Correspondence to:

Professor Gerald SWerner,

Klinik für Innere Medizin I,

Friedrich-Schiller-

Universität, Erlanger Allee

101, D-07740 Jena,

Germany; gerald.werner@

med.uni-jena.de

Accepted

23 February 2004

\begin{abstract}
Objective: To assess the potential for recovery of impaired microvascular function in collateral dependent myocardium after recanalisation of a chronic total coronary occlusion and the determinants of this recovery.

Patients and design: 120 patients underwent a successful recanalisation of a chronic total coronary occlusion (duration $>2$ weeks) and a follow up angiography after a mean (SD) of 5.0 (1.2) months. The coronary flow velocity reserve (CFVR) and the fractional flow reserve were measured after recanalisation and at follow up. Global and regional left ventricular (LV) function were analysed by quantitative angiography.

Results: Microvascular dysfunction, defined by a CFVR $<2.0$ and a fractional flow reserve $\geqslant 0.75$, was observed in $55(46 \%)$ patients after recanalisation. Microvascular function improved during follow up in $24(20 \%)$. The CFVR increased during follow up from $2.01(0.58)$ to $2.50(0.79)(p<0.001)$, due to a decrease in basal average peak velocity from $30.7(14.9) \mathrm{cm} / \mathrm{s}$ to $25.5(13.3) \mathrm{cm} / \mathrm{s}(\mathrm{p}=0.001)$. Improved microvascular function was associated with an improved regional LV function, shown by a correlation between increased wall motion severity index and increased CFVR $(r=0.38, p=0.003)$. The major determinant of microvascular dysfunction at baseline was the presence of diabetes mellitus (odds ratio $4.3,95 \%$ confidence interval 1.8 to 10.2), which remained so at follow up (odds ratio 4.1, $95 \%$ confidence interval 1.3 to 13.4). Improvement of LV function was not impaired by the presence of microvascular dysfunction after recanalisation.

Conclusions: The frequently observed microvascular dysfunction after recanalisation of a chronic total coronary occlusion is a transient phenomenon in most patients and is influenced by the presence of diabetes mellitus. It does not impede the recovery of LV function. Improved regional LV function is associated with improved microvascular function.
\end{abstract}

$\mathrm{T}$ he rationale for the recanalisation of a chronic total coronary occlusion is the possible improvement of left ventricular (LV) function through the recovery of hibernating myocardium. ${ }^{1-5}$ The opened artery may even improve survival. ${ }^{6}$ From studies on the recanalisation of acute occlusions it is known that impaired microvascular function may impede the recovery of LV function. ${ }^{78}$ However, such a relation was not observed among patients who were treated 2-3 weeks after an acute myocardial infarction. ${ }^{9}$ It is unknown whether microvascular function would affect the recovery of LV function in chronic total coronary occlusions of longer duration, which are characterised by a high prevalence of microvascular dysfunction. ${ }^{10}{ }^{11}$ Furthermore, percutaneous coronary intervention (PCI) itself poses a risk to the integrity of the microcirculation, shown by an impaired coronary flow reserve in about $10-20 \%$ of patients after PCI. ${ }^{12}{ }^{13}$ This may be attributed to microembolisation, ${ }^{14}$ which may come into play during the recanalisation of chronic total coronary occlusions with a typically large plaque burden consisting in part of organised thrombotic material. ${ }^{15} 16$

The aim of the present study was to assess whether the high prevalence of microvascular dysfunction in chronic total coronary occlusions immediately after recanalisation is a persistent disorder or whether function is recovered during long term follow up. The changes of coronary flow velocity reserve (CFVR) during follow up may provide insights into the underlying mechanisms of microvascular dysfunction in chronic total coronary occlusions. Furthermore, this study addressed whether the recovery of LV function in chronic total coronary occlusions is affected by microvascular dysfunction.

\section{METHODS \\ Patients}

In a consecutive series of 127 patients a chronic total coronary occlusion was successfully recanalised. The inclusion criteria were a duration of the occlusion $>2$ weeks and spontaneously visible collaterals. The presence of an LV aneurysm was the single exclusion criterion. A follow up angiography was available for 120 patients after 5.0 (1.2) months and they formed the study group. The study was approved by the institutional ethical committee.

\section{Angioplasty procedure}

A femoral approach with a 6 French or 7 French guiding catheter was used. All patients received a bolus of $10000 \mathrm{IU}$ heparin and were taking aspirin (100 mg). They were given clopidogrel $(75 \mathrm{mg}$ ) for four weeks starting on the day of the PCI. Stents were used in all lesions and in 55\% multiple stents were implanted. The stents were sized to achieve a

Abbreviations: APV, average peak velocity; CFVR, coronary flow velocity reserve; $\mathrm{Cl}$, confidence interval; FFR, fractional flow reserve; LV, left ventricular; LVEF, left ventricular ejection fraction; OR, odds ratio; $\mathrm{PCl}$, percutaneous coronary intervention; WMSI, wall motion severity index 
balloon to artery ratio of $1: 1$ and additional dilatations were done to achieve a residual stenosis $<20 \%$.

\section{CFVR and fractional flow reserve assessment after recanalisation}

After stent implantation a Doppler wire (FloWire, Volcano Therapeutics, Brussels, Belgium) was advanced through the stented segment and positioned with a distance to side branches of at least $5 \mathrm{~mm}$. After the baseline average peak velocity (APV) signal stabilised, adenosine at a concentration of $12 \mu \mathrm{g} / \mathrm{ml}$ was rapidly injected: $36 \mu \mathrm{g}$ into the right and $48 \mu \mathrm{g}$ into the left coronary artery. The maximum of the hyperaemic increase of APV was recorded. If an atrioventricular conduction block occurred, adenosine was reduced to a minimum of $20 \mu \mathrm{g}$ for the right and $30 \mu \mathrm{g}$ for the left coronary artery. The CFVR was calculated as the ratio of maximum hyperaemic APV to the basal APV.

Fractional flow reserve (FFR) was additionally assessed in 104 patients with a pressure wire (PressureWire, RADI Medical, Systems AB, Uppsala, Sweden) advanced about $1 \mathrm{~cm}$ distal to the stented lesion. Particular care was taken to avoid artefacts by the guiding catheter, the pressure transducer position, and the selective intracoronary injection of adenosine in the same concentration as for the CFVR. ${ }^{17} \mathrm{~A}$ simplified formula for FFR as the ratio of mean distal coronary pressure and mean aortic pressure was used. ${ }^{18}$ The measurements of CFVR and FFR were repeated three times and averaged for further analysis.

\section{Definition of microvascular dysfunction}

A cut off value for a "normal" CFVR of $\geqslant 2.0$ was used. ${ }^{19} \mathrm{~A}$ CFVR $<2.0$ after PCI was considered to indicate microvascular dysfunction in the absence of an angiographically visible residual lesion $(<20 \%$ stenosis $)$. The absence of significant epicardial resistance was confirmed in the subset of patients in whom pressure was recorded by an FFR $\geqslant 0.75$.

\section{CFVR at follow up}

CFVR was again measured at follow up in 104 patients without a restenosis or in those undergoing a successful repeat angioplasty for a recurring lesion. CFVR could not be reassessed in 16 patients with reocclusion or restenosis who did not undergo a repeat PCI. In case of a repeat PCI the CFVR after PCI was used for further analysis. In 76 of these patients the CFVR was followed by the recording of the FFR as described above.

\section{Quantitative angiography}

Coronary angiograms were analysed after PCI and at follow up with quantitative analysis software (QCA 4.0, Pie Medical Imaging, Maastricht, The Netherlands). Significant restenosis was defined as $>50 \%$ diameter stenosis at follow up. Biplane LV angiograms were obtained for all patients at the time of the baseline diagnostic procedure and were repeated at follow up. LV function was analysed with quantitative analysis software (LVA 4.0, Pie Medical Imaging). The LV ejection fraction (LVEF) was calculated and regional wall motion was analysed based on the centre line method to assess the wall motion severity index (WMSI) (SD/chord) and the extent of wall motion abnormality (number of chords) in the territory of the recanalised artery. ${ }^{20}$

\section{Subgroup analysis}

Patients with repeated CFVR assessment were categorised into three groups according to microvascular function: patients with normal microvascular function (CFVR $\geqslant 2.0$ immediately after recanalisation); patients with transient microvascular dysfunction (initial CFVR $<2.0$ that improved to $\geqslant 2.0$ at follow up); and patients with persistent

Table 1 Patients without, with transient, and with persistent microvascular dysfunction after recanalisation of a chronic total coronary occlusion

\begin{tabular}{|c|c|c|c|c|}
\hline & \multicolumn{3}{|c|}{ Microvascular dysfunction } & \multirow[b]{2}{*}{ p Value } \\
\hline & None & Transient & Persistent & \\
\hline Number of patients & 52 & 29 & 17 & \\
\hline Age (years) & $61.6(9.5)$ & $65.2(8.2)$ & $65.7(12.7)$ & 0.16 \\
\hline Prior Ml & $67 \%$ & $59 \%$ & $76 \%$ & 0.47 \\
\hline Diabetes & $13 \%^{*}$ & $41 \%$ & $59 \%$ & $<0.001$ \\
\hline Hypertension & $71 \%$ & $90 \%$ & $76 \%$ & 0.15 \\
\hline FFR & $0.87(0.07)$ & $0.86(0.09)$ & $0.87(0.09)$ & 0.91 \\
\hline Diameter restenosis (\%) & 49 (19) & $47(21)$ & $43(17)$ & 0.46 \\
\hline \multicolumn{5}{|c|}{ Coronary haemodynamic variables at baseline } \\
\hline Basal APV $(\mathrm{cm} / \mathrm{s})$ & $25.1(12.1)^{* *}$ & $35.0(12.6)$ & $40.7(18.8)$ & $<0.001$ \\
\hline Hyperaemic APV (cm/s) & $59.8(26.9)$ & $54.6(21.5)$ & $58.0(25.4)$ & 0.72 \\
\hline CFVR & $2.44(0.39)^{* *}$ & $1.57(0.26)$ & $1.46(0.21)$ & $<0.001$ \\
\hline \multicolumn{5}{|c|}{ Coronary haemodynamic variables at follow up } \\
\hline Basal APV $(\mathrm{cm} / \mathrm{s})$ & $21.5(7.3) \dagger$ & $23.5(9.9)+\dagger \dagger$ & $40.9(19.7)^{* *}$ & $<0.001$ \\
\hline Hyperaemic APV (cm/s) & $57.1(19.4)$ & $61.1(24.9)$ & $66.9(40.2)$ & 0.39 \\
\hline CFVR & $2.78(0.76)+\dagger$ & $2.67(0.60)+\dagger \dagger$ & $1.58(0.31)^{* *}$ & $<0.001$ \\
\hline \multicolumn{5}{|l|}{ LV function at baseline } \\
\hline LVEF & $0.60(0.17)$ & $0.60(0.20)$ & $0.52(0.21)$ & 0.29 \\
\hline WMSI (SD/chord) & $-1.86(1.33)$ & $-1.86(1.33)$ & $-2.64(1.27)$ & 0.09 \\
\hline Wall motion extension (chords) & $12(12)$ & $12(11)$ & $19(12)$ & 0.08 \\
\hline \multicolumn{5}{|l|}{ LV function at follow up } \\
\hline LVEF & $0.67(0.14)+t \dagger$ & $0.70(0.13)+\dagger$ & $0.57(0.24)^{*} \dagger$ & 0.03 \\
\hline WMSI (SD/chord) & $-1.28(1.32)+\dagger \dagger$ & $-0.78(0.95)+t \dagger$ & $-2.05(1.50)^{*} \dagger$ & 0.06 \\
\hline Wall motion extension (chords) & $8(12)+t$ & $4(9)+t+$ & $15(16)^{*}$ & 0.01 \\
\hline
\end{tabular}

Data are mean (SD). $p$ Values represent the results of the ANOVA.

Six patients with reocclusion at follow up are excluded.

Comparison with other groups (post hoc analysis): ${ }^{*} p<0.01$, ${ }^{* *} p<0.001$; changes within a group during follow up: $\dagger p<0.05, \dagger+p<0.005, \dagger+\uparrow p<0.001$. APV, average peak velocity; CFVR, coronary flow velocity reserve; FFR, fractional flow reserve; LV, left ventricular; LVEF, left ventricular ejection fraction; MI, myocardial infarction; WMSI, wall motion severity index. 
microvascular dysfunction (CFVR $<2.0$ at baseline and at follow up) (table 1).

Patients were further subdivided according to their global and regional LV function into three groups: patients with normal LVEF $(>0.60)$ and WMSI $(\geqslant 2.0)$ at baseline; patients with impaired LV function at baseline but improved LVEF (increase $>10 \%$ ) or WMSI (increase $>1.0$ ) at follow up; and patients with impaired LV function without improvement (table 2).

\section{Statistical analysis}

Data are given as the mean value (SD) except where indicated otherwise. Changes between baseline and follow up measurements were evaluated by a paired $t$ test. Analysis of variance, or a $\chi^{2}$ test when appropriate, was used to analyse differences between groups. A logistic regression analysis was done to assess determinants of microvascular dysfunction at baseline and at follow up. A probability level of $p<0.05$ was considered significant. The calculations were done on a personal computer with SPSS for Windows (version 11.5, SPSS Inc, Chicago, Illinois, USA).

\section{RESULTS}

\section{Clinical course after recanalisation}

During follow up of 127 patients with a successful recanalisation of a chronic total coronary occlusion three patients died suddenly and one patient died of a pulmonary embolism. Three patients without angina pectoris declined a repeat angiography. Of the remaining 120 patients $16 \%$ had a reocclusion and $37 \%$ a non-occlusive restenosis. LVEF was $0.60(0.19)$ and improved to $0.67(0.16)(p<0.001)$ during follow up, along with an improvement of the WMSI from -1.92 (1.32) to -1.29 (1.29) SD/chord ( $<<0.001$ ).

\section{CFVR after recanalisation}

At baseline a CFVR $<2.0$ was observed in 55 (46\%) patients. This was due to a higher basal APV than in patients with a CFVR $\geqslant 2.0(35.8(15.1) \mathrm{cm} / \mathrm{s} v 25.6(13.1) \mathrm{cm} / \mathrm{s} ; \mathrm{p}<0.001)$, whereas the maximum hyperaemic APV was only slightly lower $(54.5(22.5) \mathrm{cm} / \mathrm{s} v 60.6(30.0) \mathrm{cm} / \mathrm{s} ; \mathrm{p}=0.21)$. In 104 patients with additional FFR measurement, a CFVR $<2.0$ coincided with an FFR $\geqslant 0.75$ in 43 of 47 patients. This supported the presence of microvascular dysfunction in the recanalised myocardial region with only a minority of patients (four of 104) with a significant residual lesion or diffuse atherosclerosis as an explanation for a CFVR $<2$.0. It is noteworthy that these four patients all had reocclusions at follow up.

In patients with and without microvascular dysfunction, LVEF (CFVR < 2.0: 0.58 (0.19) v CFVR $\geqslant 2.0: 0.61$ (0.18); $\mathrm{p}=0.48)$ and regional WMSI were similar $($ CFVR $<2.0$ : -2.1 ( 1.3$) v$ CFVR $\geqslant 2.0:-1.8(1.3) ; \mathrm{p}=0.23)$. The major clinical difference was that $47 \%$ patients (26 of 55) with microvascular dysfunction were diabetic compared with $17 \%$ patients (11 of 65) without microvascular dysfunction $(p<0.001)$. In a logistic regression analysis diabetes mellitus was the single significant determinant of microvascular dysfunction (odds ratio (OR) 4.3, 95\% confidence interval (CI) 1.8 to 10.2 ) while hypertension had a moderate additional influence (OR 2.6, 95\% CI 1.0 to 6.9). Smoking habits, hyperlipidaemia, and regional LV function had no independent effect.

Table 2 Coronary haemodynamic variables in patients with and without improved regional and global LV function

\begin{tabular}{|c|c|c|c|c|}
\hline & \multicolumn{3}{|c|}{ Left ventricular function } & \multirow[b]{3}{*}{$\mathrm{p}$ Value } \\
\hline & \multirow[b]{2}{*}{ Normal } & \multicolumn{2}{|l|}{ Impaired } & \\
\hline & & Improved & Not improved & \\
\hline Number of patients & 40 & 24 & 34 & \\
\hline Age (years) & $64.1(9.9)$ & $60.8(9.3)$ & $64.1(10.1)$ & 0.35 \\
\hline Prior MI & $43 \%$ ** & $75 \%$ & $88 \%$ & $<0.001$ \\
\hline Diabetes & $35 \%$ & $29 \%$ & $24 \%$ & 0.57 \\
\hline Hypertension & $88 \%$ & $75 \%$ & $68 \%$ & 0.12 \\
\hline FFR & $0.86(0.08)$ & $0.87(0.08)$ & $0.87(0.06)$ & 0.83 \\
\hline Diameter restenosis (\%) & $49(20)$ & $51(15)$ & $45(20)$ & 0.26 \\
\hline \multicolumn{5}{|l|}{ LV function at baseline } \\
\hline LVEF & $0.74(0.10)^{* *}$ & $0.52(0.13)$ & $0.45(0.17)$ & $<0.001$ \\
\hline Wall motion extension (chords) & $2(3)^{* *}$ & $18(7)$ & $23(11)$ & $<0.001$ \\
\hline \multicolumn{5}{|l|}{ LV function at follow up } \\
\hline LVEF & $0.75(0.09)$ & $0.73(0.08) \dagger$ & $0.51(0.16)^{* *}+\dagger \dagger$ & $<0.001$ \\
\hline Wall motion extension (chords) & $2(3) \dagger$ & $2(4) \dagger$ & $23(10)^{\star *}$ & $<0.001$ \\
\hline \multicolumn{5}{|c|}{ Coronary haemodynamic variables at baseline } \\
\hline Heart rate (beats $/ \mathrm{min}$ ) & $69(16)$ & $69(14)$ & $70(12)$ & 0.93 \\
\hline Mean aortic pressure $(\mathrm{mm} \mathrm{Hg})$ & $102(15)$ & $107(15)$ & $98(17)$ & 0.13 \\
\hline LVEDP $(\mathrm{mm} \mathrm{Hg})$ & $13(7)^{*}$ & $19(8)$ & $18(9)$ & 0.02 \\
\hline Basal APV $(\mathrm{cm} / \mathrm{s})$ & $29.5(14.2)^{* *}$ & $32.7(14.5)$ & $30.8(16.1)$ & 0.71 \\
\hline Hyperaemic APV (cm/s) & $55.6(22.1)$ & $59.5(23.7)$ & $59.6(29.4)$ & 0.75 \\
\hline CFVR & $2.04(0.60)^{* *}$ & $1.92(0.56)$ & $2.05(0.54)$ & 0.61 \\
\hline \multicolumn{5}{|c|}{ Coronary haemodynamic variables at follow up } \\
\hline Heart rate (beats/min) & $67(15)$ & $64(10)$ & $66(13)$ & 0.77 \\
\hline Mean aortic pressure $(\mathrm{mm} \mathrm{Hg})$ & 107 (17) & $110(14)$ & $102(16)$ & 0.15 \\
\hline LVEDP $(\mathrm{mm} \mathrm{Hg})$ & $15(7)$ & $16(7) \dagger$ & $17(8)$ & 0.70 \\
\hline Basal APV $(\mathrm{cm} / \mathrm{s})$ & $24.1(13.9) \dagger$ & 23.5 (8.1)†† & $28.6(15.3)$ & 0.23 \\
\hline Hyperaemic APV $(\mathrm{cm} / \mathrm{s})$ & $57.8(24.8)$ & $60.8(22.5)$ & $62.4(28.8)$ & 0.74 \\
\hline CFVR & $2.60(0.71) \dagger \dagger \dagger$ & $2.78(1.02) \dagger \dagger \dagger$ & $2.30(0.61) \dagger$ & 0.06 \\
\hline
\end{tabular}

Data are mean (SD). $\mathrm{p}$ Values represent the results of the ANOVA.

Six patients with reocclusion are not included.

Comparison with other groups (post hoc analysis): ${ }^{*} p<0.05,{ }^{* *} p<0.001$; changes within a group during follow up: $\uparrow p<0.05, \dagger+p<0.01,+\dagger \dagger p<0.001$.

LVEDP, left ventricular end diastolic pressure. 


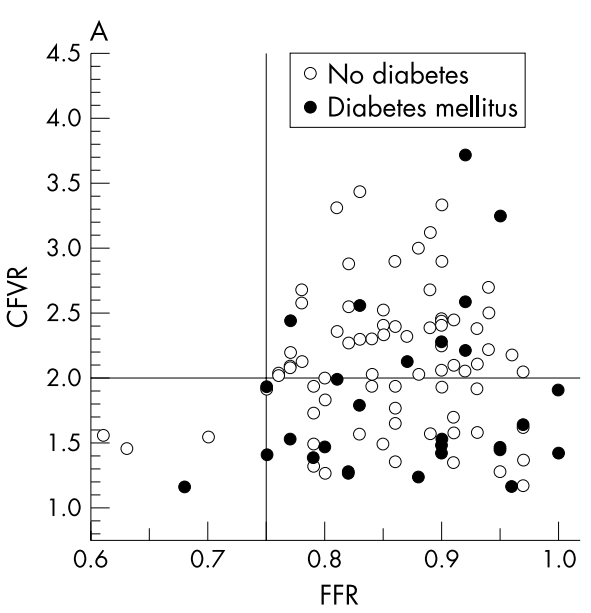

Improvement of CFVR during follow up

The CFVR was reassessed at follow up in 104 patients without restenosis $(n=57)$ or during a repeat PCI for restenosis or reocclusion $(\mathrm{n}=47)$. CFVR increased from $2.01(0.58)$ to $2.50(0.79)(\mathrm{p}<0.001)$ due to decreased basal APV (30.7 (14.9) cm/s to $25.5(13.3) \mathrm{cm} / \mathrm{s} ; \mathrm{p}=0.001)$ with unchanged hyperaemic APV. The ratio of patients with a CFVR $<2.0$ decreased from $46 \%$ after recanalisation to $26 \%$ at follow up (fig 1). In patients with a simultaneous FFR recording there was no significant correlation between CFVR and FFR at baseline $(r=0.13, \mathrm{p}=0.26)$, but a moderate correlation at follow up $(r=0.33, \mathrm{p}=0.008)$.

CFVR improved similarly in patients without restenosis and with non-occlusive restenosis, but did not change in patients who had a repeat recanalisation of a reocclusion (fig 2). The six patients with repeat recanalisation of a reocclusion were excluded from further analysis of microvascular function. In the remaining 98 patients we compared patients with a CFVR $\geqslant 2.0$ at baseline with those with no evidence of recovery of microvascular function at follow up and with those with recovery (table 1). Clinical characteristics such as prior myocardial infarction and hypertension were similar in the three groups. Diabetes mellitus was threefold more frequent in patients with transient microvascular dysfunction and fourfold more frequent in patients with persistent microvascular dysfunction compared with patients without microvascular dysfunction. The presence of diabetes did not prevent the recovery of microvascular function but CFVR did not reach the same level as in nondiabetic patients due to a persistently higher basal APV in diabetic patients (fig 3).

At baseline there was a trend towards more impairment of LV function in patients with persistent microvascular

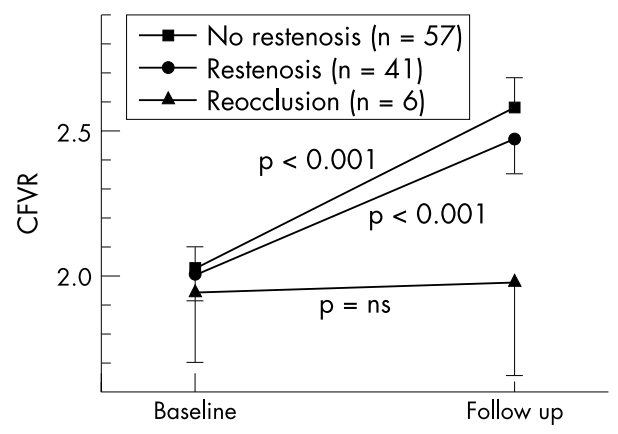

Figure 2 CFVR during follow up in patients without restenosis, with restenosis, and with reocclusion. Data shown as mean (SEM); $p$ values are for changes during follow up in each group. ns, not significant. dysfunction than in patients with normalisation of CFVR at follow up. This difference became significant at follow up. Diabetes mellitus remained the major determinant of microvascular dysfunction (OR 4.1, 95\% CI 1.3 to 13.4) but regional WMSI had an additional significant influence at follow up (OR 2.3, 95\% CI 1.1 to 4.7 ).

\section{Recovery of CFVR and LV function}

Recovery of LV function was observed in 24 of 58 (41\%) patients with initially impaired LV function. It coincided with an increase of CFVR and a decrease of basal APV (table 2). The improvement of CFVR measured as the difference between baseline and follow up measurements was correlated with the improvement of regional LV function measured as the change of WMSI (fig 4). Improvement of CFVR was not correlated with the improvement of global LV function (LVEF: $r=0.18, \mathrm{p}=0.18$ ).

\section{DISCUSSION}

This study of a consecutive, unselected cohort of patients with chronic total coronary occlusions showed that microvascular dysfunction is frequently observed in collateral dependent myocardium and persists during long term follow up mainly in patients without recovery of LV function. At baseline diabetes mellitus impairs the immediate recovery of microvascular function but after several months microvascular function can also recover in diabetic patients. The high prevalence of microvascular dysfunction after recanalisation had no adverse effect on the recovery of LV function. The mechanism of the initially impaired microvascular function appears to be a delayed recovery of resistive vessel autoregulation in the collateral dependent myocardium and is not due to an increase of perfused vascular territory. This is supported by the finding that CFVR improved because of a decrease in basal APV without an increase of hyperaemic APV.

\section{Assessment of microvascular dysfunction}

CFVR is influenced by both the epicardial resistance to flow and the microvascular resistance. In the absence of an epicardial lesion or after treatment of this lesion by PCI, a reduced CFVR would indicate an increased microvascular resistance. To help in the discrimination of epicardial and microvascular resistance, we measured $\mathrm{FFR}^{21}$ In case of diffuse atherosclerosis along the length of a coronary artery, CFVR may also be impaired due to a longitudinal perfusion gradient, ${ }^{22}$ but the combination of CFVR and FFR can also differentiate in such a setting whether flow is impaired on the epicardial or microvascular level. In fact in four of our patients this was the case. 

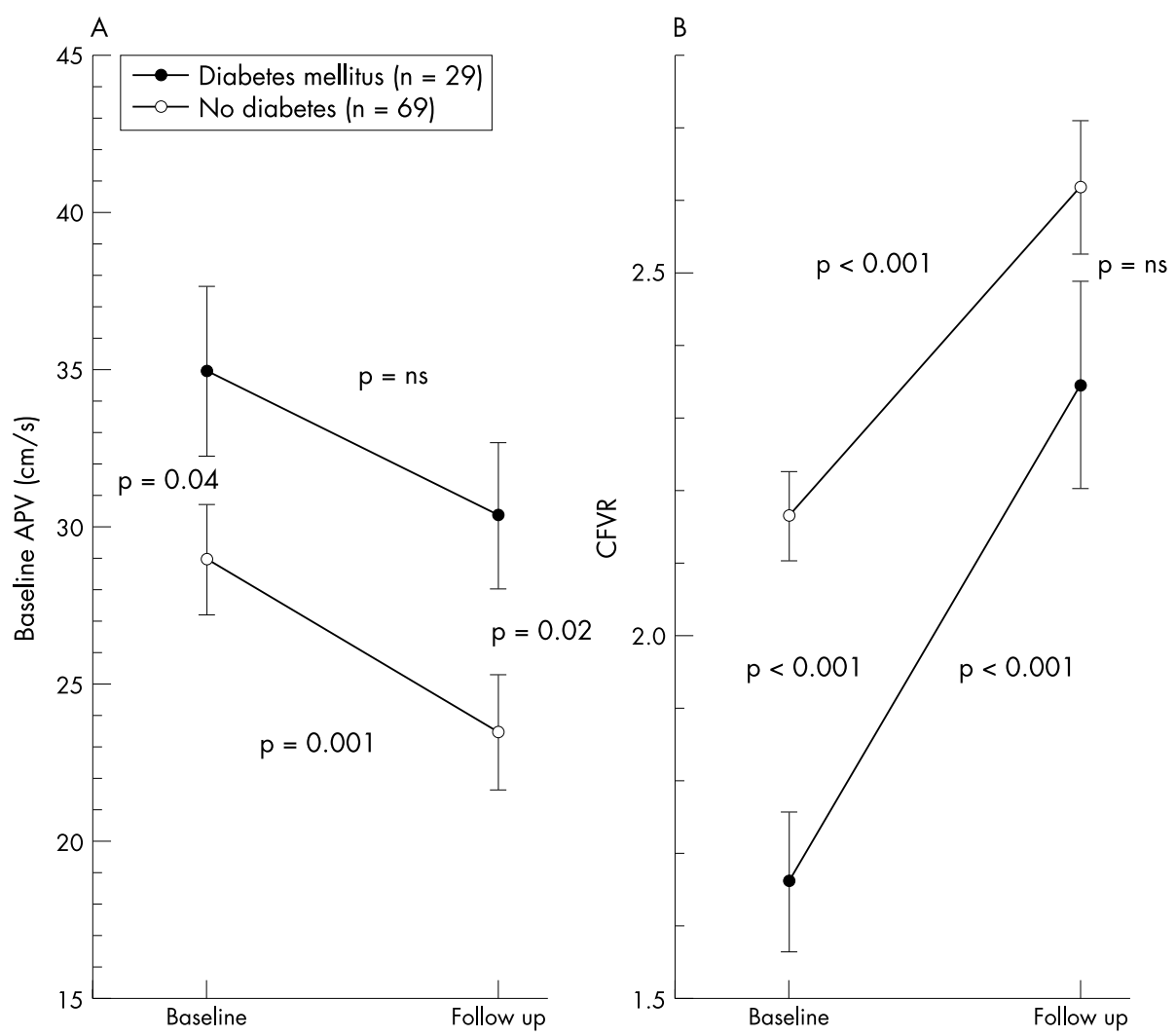

In this study we chose a cut off value of CFVR $\geqslant 2.0$ to indicate normal microvascular function. This value predicts a negative stress test for myocardial ischaemia, ${ }^{23}$ and it is applied in clinical decision making to defer angioplasty in patients with intermediate coronary lesions. ${ }^{24}{ }^{25}$ In normal patients a CFVR $<2.0$ is observed in $10-20 \%$, indicating a dysregulation of the peripheral resistive arterioles. ${ }^{26}$

\section{Recovery of microvascular function after recanalisation}

The improvement of CFVR as an indicator of microvascular function in patients with chronic total coronary occlusion and normal LV function was comparable with that observed after PTCA of non-occluded lesions. ${ }^{27-29}$ This may be due to impaired autoregulation of the resistive vessels. The improvement of CFVR in patients with initially impaired but later improved LV function at follow up results from the functional recovery of the microcirculation in hibernating myocardium. ${ }^{30}$ This is further supported by the association

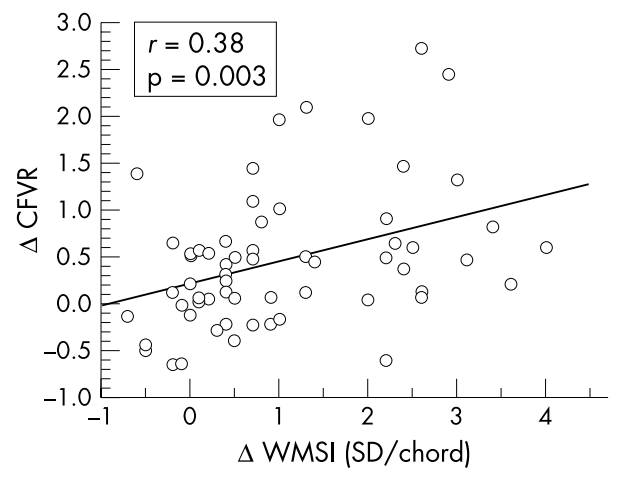

Figure 4 Relation between recovery of regional left ventricular function ( $\triangle \mathrm{WMSI}$ ) with improvement of microvascular function ( $\triangle \mathrm{CFVR}$ ) during follow up.
Figure 3 (A) Basal average peak velocity (APV) and (B) CFVR during follow up of patients with and without diabetes mellitus. Data shown as mean (SEM); $p$ values are for changes during follow up in each group and between groups. between the improvement of WMSI and CFVR. There is also evidence that in patients with prior myocardial infarction remote myocardial regions have microvascular dysfunction. ${ }^{31}$ It would be interesting to determine whether our observations of changes in the collateral dependent myocardium also extend to these remote regions.

The high basal APV after recanalisation is an indicator of considerable dilatation of peripheral resistance vessels, which would have been required for the perfusion of the collateral dependent myocardium. We recently found such a maximum vasodilatation in two thirds of chronic total coronary occlusions when systemic adenosine infusion did not further reduce the microvascular resistance. ${ }^{32}$ It is conceivable that this vasodilatation persisted after recanalisation for some time before the autoregulatory capacity of the microvasculature was finally restored.

Another explanation for the improved CFVR is an increase of the perfused vascular bed. In studies with intracoronary Doppler in acute myocardial infarction, reduced basal and hyperaemic APV were observed to cause low CFVR. ${ }^{33}{ }^{34}$ There the improvement of CFVR was explained by reopening of obstructed vascular beds. In chronic total coronary occlusions the basal APV was rather high and the hyperaemic APV did not change, which makes the recruitment of reperfused vascular territory an unlikely explanation. Finally, reduced CFVR may also be caused by a microembolism during the recanalisation procedure. ${ }^{35}$ However, a recent analysis from our laboratory found no correlation between troponin I release within 24 hours after recanalisation and the impairment of CFVR. ${ }^{36}$

Reduced CFVR after recanalisation did not impede the recovery of LV function and, unlike in non-occlusive lesions with normal LV function, ${ }^{37}$ the observation of reduced CFVR after percutaneous transluminal coronary angioplasty did not predict an adverse long term outcome. ${ }^{39}$ However, our observation of reocclusion in all of the few patients who had both a low FFR and a low CFVR after recanalisation suggests 
that this coincidence may identify lesions at increased risk of reocclusion.

\section{The influence of diabetes mellitus on microvascular function in chronic total coronary occlusions}

Almost half of all patients with a chronic total coronary occlusion showed evidence of microvascular dysfunction immediately after recanalisation, which was predominantly due to the presence of diabetes mellitus as a co-morbidity. However, improved CFVR was observed both in diabetic and in non-diabetic patients. Recovery of the microvascular autoregulation was delayed in diabetic patients but not impeded. There was also a considerable potential for microvascular recovery in diabetic patients but it did not reach the level of recovery in non-diabetic patients because basal APV remained higher in diabetic patients. ${ }^{40}{ }^{41}$

\section{Study limitations}

The definition of microvascular dysfunction was based on reduced CFVR. In the majority of patients we supported this by additionally recording FFR. The technical and conceptual limitations of this approach had been previously addressed in detail. ${ }^{11}{ }^{13}{ }^{19}$ We had confirmed the presence of microvascular dysfunction in the subset of patients with simultaneous CFVR and FFR, and we observed diffuse atherosclerosis as another possible factor of reduced CFVR in only 5\% where FFR was also abnormal. The coincidence of low CFVR and FFR was similar at follow up.

We excluded patients with reocclusion from the analysis of microvascular recovery but we included patients with restenosis in whom CFVR was measured after repeat PCI. This repeat PCI itself may have influenced CFVR and may have overestimated the prevalence of microvascular dysfunction at follow up. However, CFVR improved both in patients with and in patients without restenosis at follow up, which indicated that the repeat intervention for a non-occlusive restenosis was not the major determinant of microvascular dysfunction.

\section{Conclusions}

The frequently observed microvascular dysfunction after recanalisation of a chronic total coronary occlusion is a transient phenomenon in most patients and is influenced mainly by the presence of diabetes mellitus. Diabetes also has an adverse influence on microvascular function at follow up. Microvascular dysfunction in chronic total coronary occlusions does not impede the recovery of LV function and it improves during follow up both in patients with normal LV function and in patients with recovered LV function after recanalisation. The initially low CFVR after PCI appears to be due to delayed restoration of the autoregulation of the microvasculature in collateral dependent myocardium.

\section{Authors' affiliations}

G S Werner, U Emig, P Bahrmann, M Ferrari, H R Figulla, Clinic for Internal Medicine I, Friedrich Schiller University Jena, Jena, Germany

\section{REFERENCES}

1 Melchior JP, Doriot PA, Chatelain P, et al. Improvement of left ventricular contraction and relaxation after recanalization of chronic total coronary occlusions by angioplasty. J Am Coll Cardiol 1987;9:763-8.

2 Sirnes PA, Myreng Y, Molstad P, et al. Improvement of left ventricular ejection fraction and wall motion after successful recanalization of chronic coronary occlusions. Eur Heart J 1998; 19:273-81

3 Fath-Ordoubadi F, Beatt KJ, Spyrou N, et al. Efficacy of coronary angioplasty for the treatment of hibernating myocardium. Heart 1999:82:210-6.

4 Vanoverschelde JL, Wijns W, Depré C, et al. Mechanisms of chronic regional postischemic dysfunction in humans: new insights from the study of noninfarcted collateral-dependent myocardium. Circulation 1993;87:1513-23.
5 Shivalkar B, Maes A, Borgers $M$, et al. Only hibernating myocardium invariably shows early recovery after coronary revascularization. Circulation 1996;94:308-15.

6 Suero JA, Marso SP, Jones PG, et al. Procedural outcomes and long-term survival among patients undergoing percutaneous coronary intervention of a chronic total occlusion in native coronary arteries: a 20 -year experience. J Am Coll Cardiol 2001;38:409-14.

7 Mazur W, Bitar JN, Lechin M, et al. Coronary flow reserve may predict myocardial recovery after myocardial infarction in patients with TIMI grade 3 flow. Am Heart J 1998;136:335-44.

8 Teiger E, Garot J, Aptecar E, et al. Coronary blood flow reserve and wall motion recovery in patients undergoing angioplasty for myocardial infarction. Eur Heart J 1999;20:285-92.

9 Claeys MJ, Vrints CJ, Bosmans J, et al. Coronary flow reserve during coronary angioplasty in patients with recent myocardial infarction: relation to stenosis and myocardial viability. J Am Coll Cardiol 1996;28:1712-9.

10 Sambuceti G, Parodi O, Giorgetti A, et al. Microvascular dysfunction in collateral-dependent myocardium. J Am Coll Cardiol 1995;26:615-23.

11 Werner GS, Ferrari M, Richartz BM, et al. Microvascular dysfunction in chronic total coronary occlusions. Circulation 2001;104:1129-34.

12 Wilson RF, Johnson MR, Marcus ML, et al. The effect of coronary angioplasty on coronary flow reserve. Circulation 1988;77:873-85.

13 Kern MJ, Puri S, Bach RG, et al. Abnormal coronary flow velocity reserve after coronary artery stenting in patients: role of relative coronary reserve to assess potential mechanisms. Circulation 1999;100:2491-8.

14 Brener SJ, Topol EJ. Epicardial versus microcirculatory dissociation. Eur Heart J 2002;23:274-6.

15 Katsuragawa $M$, Fujiwara $\mathrm{H}$, Miyamae $M$, et al. Histologic studies in percutaneous transluminal coronary angioplasty for chronic total occlusion: comparison of tapering and abrupt types of occlusion and short and long occluded segments. J Am Coll Cardiol 1993;21:604-11.

16 Werner GS, Diedrich J, Morguet AJ, et al. Morphology of chronic coronary occlusions and response to interventional therapy: study by intracoronary ultrasound. Int J Cardiac Imaging 1997; 13:31 1-21.

17 Pijls NH, Kern MJ, Yock PG, et al. Practice and potential piffalls of coronary pressure measurement. Catheter Cardiovasc Interv 2000;49:1-16.

18 De Bruyne B, Baudhuin T, Melin JA, et al. Coronary flow reserve calculated from pressure measurements in humans: validation with positron emission tomography. Circulation 1994;89:1013-22.

19 Kern MJ, DeBruyne B, Pijls NHJ. From research to clinical practice: current role of physiologically based decision making in the catheterization laboratory. J Am Coll Cardiol 1997;30:613-20.

20 Sheehan FH, Bolson EL, Dodge HT, et al. Advantages and applications of the centerline method for characterizing regional ventricular function. Circulation 1986;74:293-305.

21 Pijls NH, De Bruyne B, Peels K, et al. Measurement of fractional flow reserve to assess the functional severity of coronary-artery stenoses. N Engl J Med 1996;334:1703-8

22 De Bruyne B, Hersbach F, Pijls NHJ, et al. Abnormal epicardial coronary resistance in patients with diffuse atherosclerosis but "normal" coronary angiography. Circulation 2001;104:2401-6.

23 Tron C, Donohue TJ, Bach RG, et al. Comparison of pressure-derived fractional flow reserve with poststenotic coronary flow velocity reserve for prediction of stress myocardial perfusion imaging results. Am Heart $J$ 1995; 130:723-33.

24 Kern MJ, Donohue TJ, Aguirre FV, et al. Clinical outcome of deferring angioplasty in patients with normal translesional pressure-flow velocity measurements. J Am Coll Cardiol 1995;25:178-87.

25 Ferrari M, Schnell B, Werner GS, et al. Safety of deferring angioplasty in patients with normal coronary flow velocity reserve. J Am Coll Cardiol 1999;33:83-7.

26 Kern MJ, Bach RG, Mechem CJ, et al. Variations in normal coronary vasodilatory reserve stratified by artery, gender, heart transplantation and coronary artery disease. J Am Coll Cardiol 1996;28:1 154-60.

27 Nanto S, Kodama K, Hori M, et al. Temporal increase in resting coronary blood flow causes an impairment of coronary flow reserve after coronary angioplasty. Am Heart J 1992;123:28-36.

28 Uren NG, Crake T, Lefroy DC, et al. Delayed recovery of coronary resistive vessel function after coronary angioplasty. J Am Coll Cardiol 1993;21:612-21

29 Van Liebergen RAM, Piek JJ, Koch KT, et al. Immediate and long-term effect of balloon angioplasty or stent implantation on the absolute and relative coronary blood flow velocity reserve. Circulation 1998;98:2133-40.

30 Vanoverschelde JLJ, Depré C, Gerber BL, et al. Time course of functional recovery after coronary artery bypass graft surgery in patients with chronic left ventricular ischemic dysfunction. Am J Cardiol 2000;85:1432-9.

31 Uren NG, Crake T, Lefroy DC, et al. Reduced coronary vasodilator function in infarcted and normal myocardium after myocardial infarction. N Engl J Med 1994;331:222-7.

32 Werner GS, Figulla HR. Direct assessment of coronary steal and associated changes of collateral hemodynamics in chronic total coronary occlusions. Circulation 2002;106:435-40.

33 Suryapranata H, Zij|stra F, MacLeod DC, et al. Predictive value of reactive hyperemic response on reperfusion on recovery of regional myocardial function after coronary angioplasty in acute myocardial infarction. Circulation 1994;89:1 109-17.

34 Neumann F, Blasini R, Schmitt C, et al. Effect of glycoprotein Ilb/llla receptor blockade on recovery of coronary flow and left ventricular function after the placement of coronary artery stents in acute myocardial infarction. Circulation 1998:98:2695-701.

35 Herrmann J, Haude M, Lerman A, et al. Abnormal coronary flow velocity reserve after coronary intervention is associated with cardiac marker elevation. Circulation 2001;103:2339-45. 
36 Bahrmann $P$, Jantz $M$, Figulla $H R$, et al. Coronary microembolisation: its role in chronic total coronary occlusions and interventions [abstract]. Eur Heart $J$ 2002;23(abstract suppl):437.

37 Serruys PW, di Mario C, Piek J, et al. Prognostic value of intracoronary flow velocity and diameter stenosis in assessing the short- and long-term outcomes of coronary balloon angioplasty: the DEBATE study (Doppler endpoints balloon angioplasty trial Europe). Circulation 1997;96:3369-77.

38 Nishida T, Di Mario C, Kern MJ, et al. Impact of final coronary flow velocity reserve on late outcome following stent implantation. Eur Heart $J$ 2002;21:531-40
39 Werner GS, Bahrmann P, Mutschke O, et al. Determinants of target vessel failure in chronic total coronary occlusions after stent implantation: the influence of collateral function and coronary hemodynamics. J Am Coll Cardiol 2003;44:219-25.

40 Nahser PJ, Brown RE, Oskarsson H, et al. Maximal coronary flow reserve and metabolic coronary vasodilation in patients with diabetes mellitus. Circulation 1995;91:635-40.

41 Nitenberg A, Valensi P, Sachs R, et al. Impairment of coronary vascular reserve and $\mathrm{ACH}$-induced coronary vasodilation in diabetic patients with angiographically normal coronary arteries and normal left ventricular systolic function. Diabetes 1993;42:1017-25.

\section{IMAGES IN CARDIOLOGY}

\section{Percutaneous sealing of coronary aneurysm by grafted stent implantation}

A

72 year old man was admitted to our clinic because of recurrent angina pectoris on the 20th day of an acute anterior myocardial infarction. He had been treated with metoprolol, quinapril, isosorbide mononitrate, aspirin, and simvastatin. Coronary angiography revealed two stenotic lesions in the mid portion of left anterior descending artery. The first lesion was about $80 \%$, the second was about $60 \%$, and there was a coronary aneurysm in between the lesions (upper panels). Placement of a direct grafted stent was decided upon. After passing the lesions with a 0.014 inch guide wire, a $3.0-16 \mathrm{~mm}$ grafted stent (Jostent coronary stent graft) was advanced over the wire to cover the two lesions and the aneurysm, and was expanded. Final angiography showed no residual stenosis and no more contrast flow into the aneurysm (lower panels). A loading dose of $350 \mathrm{mg}$ clopidogrel, followed by $75 \mathrm{mg}$ daily, was added to the patient's therapeutic regimen. The patient remained symptom-free after the procedure, and a treadmill exercise test was normal at two months following the procedure.

M K Erol

E Bozkurt

S Arslan

mkerol@superonline.com.tr
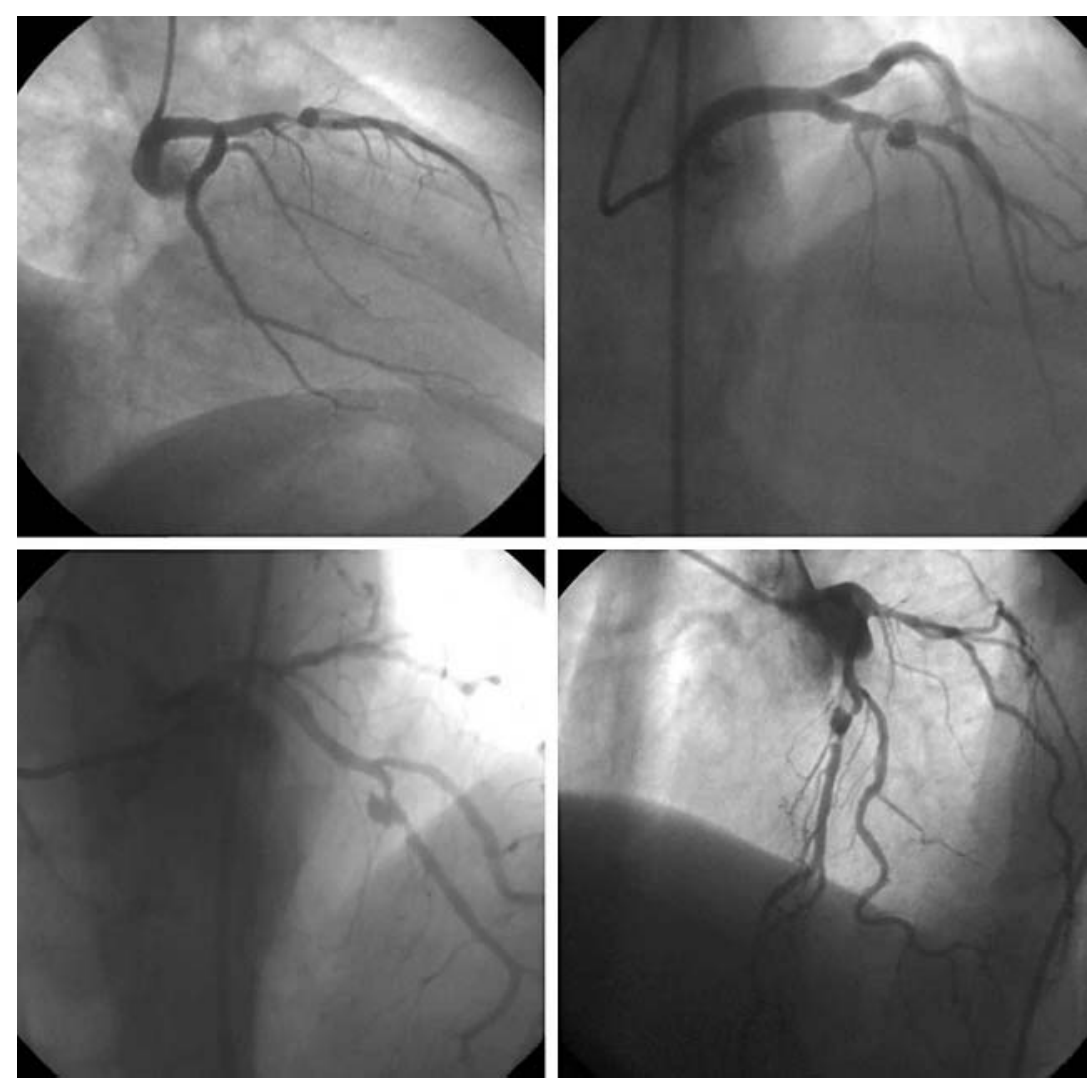

Left coronary artery in different angiographic views: two stenoses are present, with an aneurysm in between them.
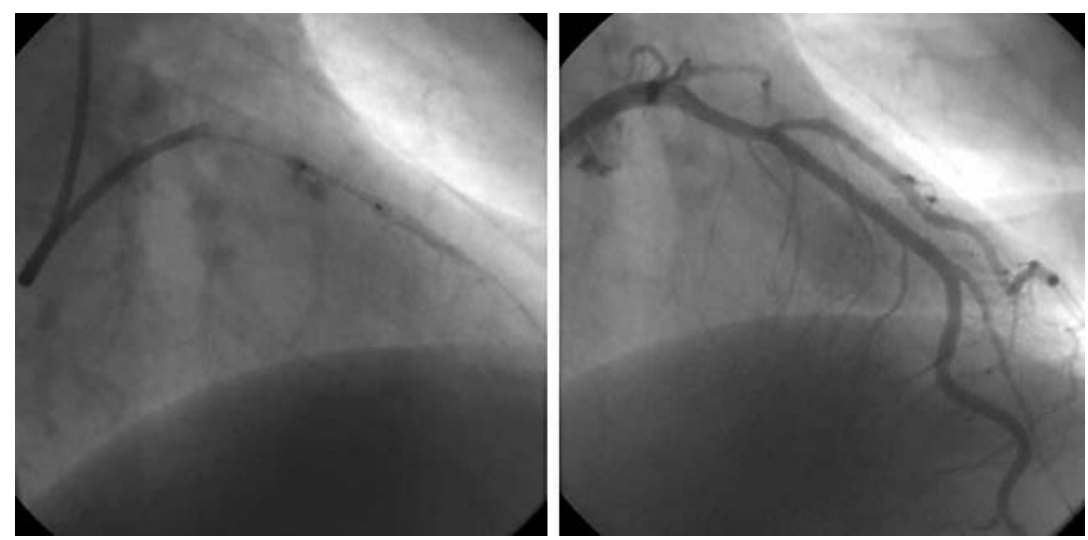

Direct grafted stent placement before (left) and after (right) inflation. Note that the aneurysm is completely sealed and there is no residual stenosis. 